\title{
Inequality in the Built Environment Underlies Key Health Disparities in Physical Activity and Obesity
}

\author{
Penny Gordon-Larsen, PhDa, Melissa C. Nelson, PhD, RD ${ }^{b}$, Phil Page, MAc, Barry M. Popkin, PhDa \\ aDepartment of Nutrition, Schools of Public Health and Medicine, Carolina Population Center, and cSpatial Analysis Unit, Carolina Population Center, University of North \\ Carolina, Chapel Hill, North Carolina; 'bivision of Epidemiology and Community Health, University of Minnesota, Minneapolis, Minnesota
}

The authors have indicated they have no financial relationships relevant to this article to disclose.

\section{ABSTRACT}

CONTEXT.Environmental factors are suggested to play a major role in physical activity (PA) and other obesity-related behaviors, yet there is no national research on the relationship between disparity in access to recreational facilities and additional impact on PA and overweight patterns in US adolescents.

OBJECTIVE. In a nationally representative cohort, we sought to assess the geographic and social distribution of PA facilities and how disparity in access might underlie population-level PA and overweight patterns.

DESIGN, SETTING, AND PARTICIPANTS. Residential locations of US adolescents in wave I (1994$1995)$ of the National Longitudinal Study of Adolescent Health $(N=20745)$ were geocoded, and a 8.05-km buffer around each residence was drawn $(N=42857$ census-block groups [19\% of US block groups]). PA facilities, measured by national databases and satellite data, were linked with Geographic Information Systems technology to each respondent. Logistic-regression analyses tested the relationship of PA-related facilities with block-group socioeconomic status (SES) (at the community level) and the subsequent association of facilities with overweight and PA (at the individual level), controlling for population density.

MAIN OUTCOME MEASURES. Outcome measures were overweight (BMI $\geq 95$ th percentile of the Centers for Disease Control and Prevention/National Center for Health Statistics growth curves) and achievement of $\geq 5$ bouts per week of moderatevigorous PA.

RESULTS. Higher-SES block groups had a significantly greater relative odds of having 1 or more facilities. Low-SES and high-minority block groups were less likely to have facilities. Relative to zero facilities per block group, an increasing number of facilities was associated with decreased overweight and increased relative odds of achieving $\geq 5$ bouts per week of moderate-vigorous PA.

CONCLUSIONS. Lower-SES and high-minority block groups had reduced access to facilities, which in turn was associated with decreased PA and increased overweight. Inequality in availability of PA facilities may contribute to ethnic and SES disparities in PA and overweight patterns. www.pediatrics.org/cgi/doi/10.1542/ peds.2005-0058

doi:10.1542/peds.2005-0058

Those who are interested in obtaining data files from Add Health should contact Add Health, Carolina Population Center, 123 W Franklin St, Chapel Hill, NC 27516-2524 (www.cpc.unc.edu/addhealth).

\section{Key Words}

environment, health disparities, adolescence, environmental health, population-based studies

\section{Abbreviations}

PA—physical activity

SES-socioeconomic status

GIS-Geographic Information Systems SIC - Standard Industrial Classification MVPA — moderate-vigorous physical activity

MET_-metabolic equivalent

CDC - Centers for Disease Control and Prevention

NCHS - National Center for Health

Statistics

OR_-odds ratio

$\mathrm{Cl}$ - confidence interval

Accepted for publication Apr 11, 2005 Address correspondence to Penny GordonLarsen, PhD, University of North Carolina, Carolina Population Center, University Square, 123 W Franklin St, Chapel Hill, NC 27516-3997. E-mail: gordon_larsen@unc.edu

PEDIATRICS (ISSN Numbers: Print, 0031-4005 Online, 1098-4275). Copyright $\odot 2006$ by the American Academy of Pediatrics 
U NDERSTANDING THE CAUSES of health disparities is critical for improving health and reducing social inequality. Inequality in obesity and its underlying factors, in particular physical activity (PA) and inactivity, contribute greatly to health disparity. Minority and groups of low education are at highest risk for obesity and most other major noncommunicable diseases..$^{1,2}$

Considerable research indicates that socioeconomic status (SES) at the neighborhood level is related to obesity, PA, and other health-related behaviors. ${ }^{3-7}$ Moreover, limited research shows that access to community facilities is positively associated with PA levels..$^{8-11} \mathrm{In}$ fact, this area of research is being strongly encouraged by both the National Institutes of Health ${ }^{12}$ and the RobertWood Johnson Foundation. ${ }^{13}$ However, there are no population-level analyses on the relationship between SES and the distribution of recreational facilities. Furthermore, there are very few studies investigating the relationship between neighborhood facilities and PA and obesity patterns in large and diverse populations.

This study fills a critical gap by examining the potential role that the built environment might play in inequality of PA and obesity at the national level with a large, ethnically diverse sample of adolescents and exact measures of PA-related facilities. Understanding physical environment factors such as the possible inequitable distribution of such resources is important for public policy related to ameliorating health disparities. ${ }^{14}$

\section{SUBJECTS AND METHODS}

\section{Survey Design}

The study population consisted of $>20000$ adolescents enrolled in Add Health, a longitudinal, nationally representative, school-based study of US adolescents in grades 7 to 12 that was supplemented with minority special samples and collected under protocols approved by the University of North Carolina Institutional Review Board. The primary sampling frame included a sample of 80 US high schools and 52 US middle schools with unequal probability of selection. The study design included systematic sampling methods and implicit stratification to ensure representation of US schools with respect to region of country, urbanicity, school size, school type, and ethnicity; the analyses account for cluster sampling. Confidentiality does not permit disclosure of the location of the Add Health communities.

\section{Respondent-Location Data}

All Add Health respondents had residential street addresses that were recorded at each interview. Residential street addresses were geocoded by a commercial geocoding services vendor, Geographic Data Technology (now TeleAtlas, Lebanon, New Hampshire). Respondent residences that could not be properly address-geocoded had their positions recorded by using global positioning system devices. Locations for wave I respondents were then assigned from the best available source in the following priority order: addresses geocoded with street segment match ( $N=17119)$, addresses geocoded with global positioning system $(N=3242)$, addresses geocoded with zip code +4 or zip code +2 centroid match $(N=163)$, addresses geocoded with 5 -digit zip-code centroid match $(N=88)$, and addresses geocoded by the respondent's school location $(N=133)$. For respondents with problematic wave I (1994-1995) location data, wave II (1996) location information was substituted if the respondent information indicated that they had not moved. Two adjustments were made to the resulting data layer. The 163 respondents with residential locations $>75$ miles from their schools were presumed to be in error and were reassigned to their school locations. During data quality review of the respondent-location data layer, the respondent locations based on Geographic Data Technology address geocoding in $1 \mathrm{com}-$ munity seemed to be systematically offset from their correct locations when compared with digital orthophotography for the area. These respondent locations were adjusted to match the geography shown in the orthophotography by using a standardized Geographic Information Systems (GIS) "rubber-sheeting" operation. ${ }^{15}$

An 8.05-km (5-mile) buffer was drawn around each respondent, on the basis of empirical evidence that this distance would likely capture relevant PA facilities. ${ }^{16,17}$ An $8.05-\mathrm{km}$ buffer was built around each respondent $(N$ $=20745$ ), and then all were aggregated to create the full set of 42857 census-block groups used in this study. In this study, the buffers were used for the sole purpose of generating the large sample of census-block groups that are described below.

\section{Census-Block-Group Locations}

The $8.05-\mathrm{km}$ circular buffers for each respondent were combined to form an aggregated buffer data layer. A GIS polygon-on-polygon overlay combined the aggregate buffers and the census-block-group boundaries. All census-block groups in which a respondent residence was located, plus all census-block groups fully subsumed within the aggregate buffers, were included in the sample ( $N=42857$ census-block groups) except block groups that represented military/merchant ships. A GIS point-in-polygon overlay was performed to select all the PA facilities and resources located within these censusblock groups (Fig 1).

\section{Census Variables}

Census variables (reported at the block-group level) were extracted from the 1990 Census of Population and Housing Summary Tape File 3A. A census-block group is the second-lowest-level geographic entity, generally containing between 300 and 3000 people. Variables included population density (total number of individ- 

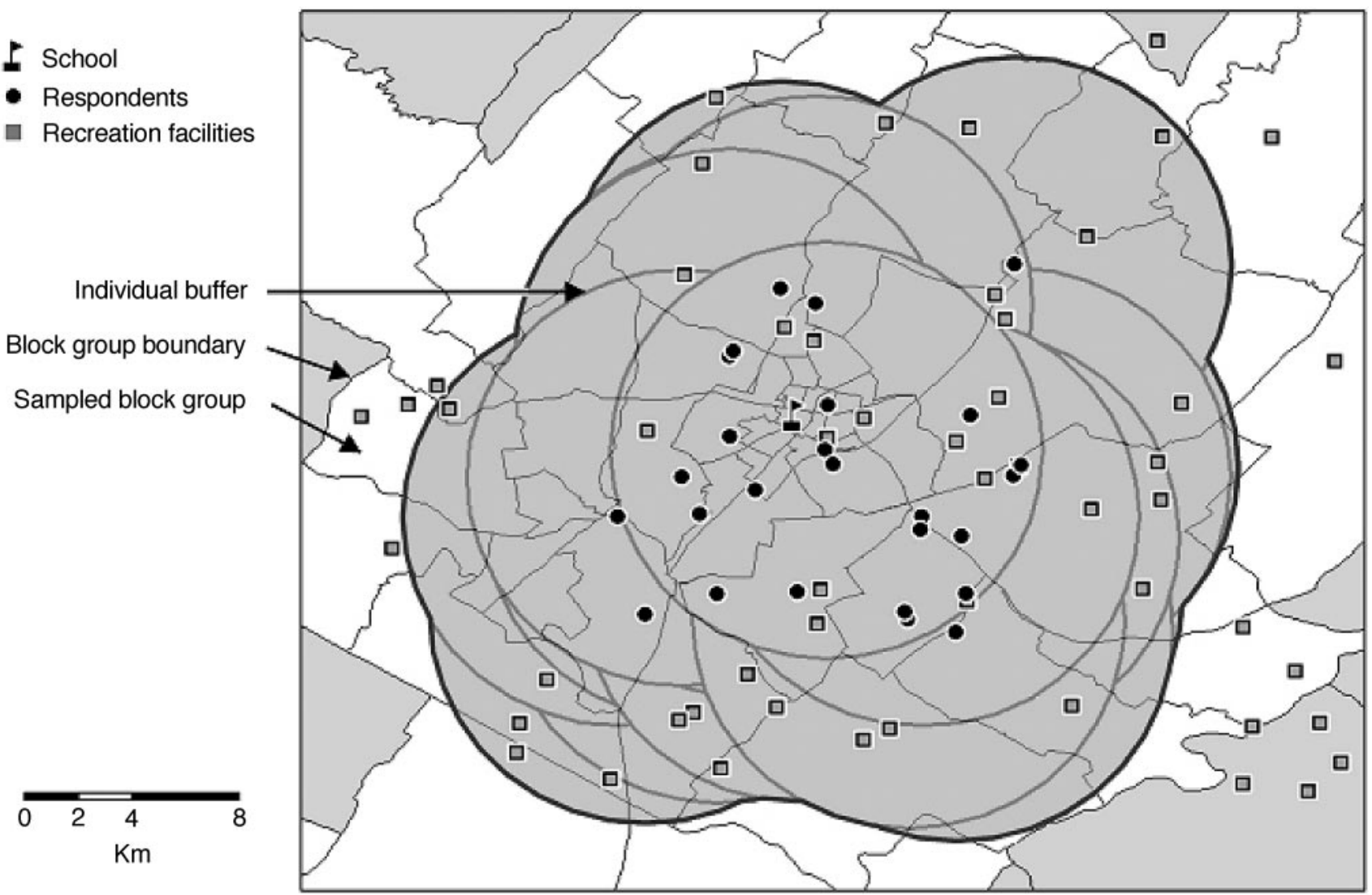

FIGURE 1

Sampling strategy for the study: Add Health neighborhoods, 42857 block groups (19\% of United States) within $8.05 \mathrm{~km}$ (5 miles) of each respondent (a fabricated location is shown, not the actual Add Health study community or respondents).

uals in a block group divided by the block-group area reported in square miles), proportion of population with college degree or higher, and nonwhite (ethnic minority) proportion of the population. Education level of the census-block group is used as the primary indicator of SES, given empirical evidence of the greater connection between education and health outcomes than income $^{18,19}$ and particularly given its association with PA. ${ }^{20}$

\section{PA Facilities and Resources}

A commercially purchased set of digitized business records recorded in a proprietary 4-digit extension to the 4-digit Standard Industrial Classification codes (SIC) were used. These detailed 8-digit SIC codes are identical to those used by the Census Bureau. Comprehensive retrospective data for time period of interest were used. The standard set of data used for addresses and linkage to facilities from commercial databases provides 6-digit SIC codes, which do not provide depth in categorization of facilities or accurate retrospective data (ie, most databases include only facilities that are currently in business).

A comprehensive list of 169 of the 8-digit SIC codes for PA facilities and resources was built. YMCA/YWCA facilities do not have unique SIC identifiers, so a textual query was developed to select them based on the facility name field in the database. The SIC code list, YMCA/ YWCA query, and zip codes encompassing the respondent $8.05-\mathrm{km}$ buffers were sent to the commercial vendor. All records of interest matching the criteria and falling within the zip-code areas specified were returned along with facility names and street addresses contemporaneous to the wave I calendar year 1995. Facility locations were geocoded by using ESRI StreetMap 20001.1 (Environmental Systems Research Institute, Inc, Redlands, CA) (which uses street and address data from Geographic Data Technology), with an address-geocoding match rate of $85.9 \%$. An additional $8.2 \%$ of the facilities were located by using latitude and longitude coordinates that were provided by the commercial vendor, yielding a total of $94.1 \%$ of the 71286 records returned from the commercial vendor that were entered into the recreational-facilities GIS data layer.

Measures of recreational facilities were derived from the larger list of SIC resources. The SIC codes were summarized into a single measure of all facilities and subdivided into smaller categories of specific types of facilities, with some overlap between categories (eg, outdoor facilities and public facilities) (Table 1). 


\begin{tabular}{|c|c|}
\hline Facility Type & Examples \\
\hline Schools & $\begin{array}{l}\text { Elementary and secondary schools, colleges, } \\
\text { universities }\end{array}$ \\
\hline Public facilities & $\begin{array}{l}\text { Public beach, pools, tennis courts, recreation } \\
\text { centers }\end{array}$ \\
\hline Youth organizations & Boy/Girl Scouts, youth centers \\
\hline Parks & Parks and recreation services \\
\hline YMCA & YMCA, YWCA \\
\hline Public fee facilities & $\begin{array}{l}\text { Physical fitness facilities, bicycle rental, public golf } \\
\text { courses }\end{array}$ \\
\hline Instruction & Dance studios, basketball instruction, martial arts \\
\hline Outdoor & Sporting and recreational camps, swimming pools \\
\hline Member & $\begin{array}{l}\text { Athletic club and gymnasium, tennis club, } \\
\text { basketball club }\end{array}$ \\
\hline All facilities & All recreation facilities across categories \\
\hline
\end{tabular}

\section{Database Integration}

Databases were aligned spatially and temporally (Fig 1). The separate layers for respondents and schools and their respective $8.05-\mathrm{km}$ buffers were combined with the layers containing census-block-group geography and zip-code polygons. Finally, the data layer representing PA facilities by SIC code was added. Because this is a national study, the GIS data layers were segmented into 11 Universal Transverse Mercator coordinate system zones by using North American Datum 1983 to prevent introducing the geographic distortions present in a single-map projection and coordinate system spanning the country.

\section{Moderate-Vigorous PA}

The wave I questionnaire included a standard PA-behavior recall ${ }^{8,21}$ that is similar to other self-report questionnaires that have been used and validated in other largescale epidemiologic studies. ${ }^{22-25}$ Information was elicited on participation in moderate-vigorous PA (MVPA) (5-8 metabolic equivalents (METs); skating and cycling, exercise, and active sports) in the previous week. One MET is defined as the energy expenditure associated with quiet sitting. The Add Health PA questions were worded as such, "During the past week, how many times did you..." followed by a listing of activities such as walking, basketball, softball, and so forth, allowing calculation of frequency (bouts) of specified activities per week by MET value. A binary variable was created to represent whether the respondent achieved $\geq 5$ bouts of MVPA per week. Those with missing data were excluded.

\section{Body Mass}

Height and weight were self-reported in wave I during in-home surveys, and overweight status was defined as a BMI $\geq 95$ th percentile of age- and gender-specific cut points from the 2000 Centers for Disease Control and Prevention (CDC)/National Center for Health Statistics (NCHS) growth charts. ${ }^{26}$ Those with missing data were excluded.
Given their correlation with measured height and weight and the acceptance of self-report measures in epidemiologic studies, self-reported height and weight were used. ${ }^{27}$

\section{Statistical Analysis}

This is a descriptive ecological study investigating the association between block-group-level sociodemographic factors and availability of PA and recreational facilities. In addition, the association between community PA and recreational facilities and individual-level PA and overweight was assessed. Statistical analyses were conducted by using Stata 8.2.28 Three sets of logistic-regression models were run at 2 distinct levels (national and individual): (1) population-level models that tested the relative odds of having $\geq 1$ of various types of recreational facilities by census-level education status, controlling for the proportion of the census-level population of nonwhite ethnicities $(N=42187 ; 651$ were missing block-group education and minority data, and 19 were missing block-group education data); (2) interactive population-level models (minority census-level population $\times$ census-level education status) that tested the relative odds of having $\geq 1$ recreational facility per block group at combined levels of census-level education and minority population $(N=42187)$; and (3) individual-level analyses that assessed the association between number of facilities within an individuals' residential block group and relative odds of overweight (BMI $\geq 95$ th percentile of the CDC/NCHS growth curves; $N=17$ 950) and high MVPA ( $\geq 5$ bouts of MVPA per week; $N=$ 18413 ). To retain comparability of our research with other disparity-related research, this analysis maintains the census-block-group definition of neighborhood for the individual-level analyses. Individual-level models assessed only the census-block group in which the individual resided. No analyses were made at the buffer level in this study. All models controlled for population density within the block group.

The widely accepted series of Stata survey procedures were used to correct SEs for multiple stages of cluster sample design in models predicting the likelihood of overweight and PA.

\section{RESULTS}

The study area comprised 42857 census-block groups (summary statistics are reported in Table 2). The sample represents a wide variety of demographic characteristics.

Census-block groups with a higher proportion of college- (or greater) educated populations were significantly more likely to have a wide variety of PA facilities compared with less-advantaged block groups (Fig 2). The relative odds of having at least 1 facility also decreased as minority population increased. The relative odds of having at least 1 PA facility was significant for all types of facilities (odds ratio [OR]: 2.18; 95\% confidence 


\section{Facility Type}

Census-block group-level variables ( $N=42857)$

Mean proportion of college-educated population, $\%$ (SE)

Mean proportion of ethnic minority (nonwhite) population, \% (SE)

Mean population density (per square mile) (SE)

Mean no. (SE) of facilities per block group

Mean proportion of block groups with $\geq 1$ facility, $\%$ (SE)

Individual-level variables $(N=17950)^{\text {a }}$

Mean no. of respondents per block group (SE)

Mean proportion of overweight, \% (SE) $)^{\mathrm{b}, \mathrm{c}}$

Mean proportion of sample achieving high MVPA, $\%(\mathrm{SE}) \mathrm{c}, \mathrm{d}$

a Individual-level variables were weighted to be nationally representative.

b Overweight was defined as a BMI $\geq 95$ th percentile of the CDC/NCHS 2000 growth curves; nonoverweight was defined as a $\mathrm{BMl}<95$ th percentile.

CSEs were corrected for the complex survey design.

${ }^{\mathrm{d}}$ High MVPA was defined as $\geq 5$ bouts of MVPA per week; low MVPA was defined as $<5$ bouts of MVPA per week.

interval [CI]: 1.94-2.44). Thus, for every $100 \%$ increase in the proportion of individuals in a census-block group with college or greater education, there is a greater than twofold increase in facility access. The highest relative odds of having a PA facility was found for outdoor (OR: 4.20; 95\% CI: 3.32-5.31) and private-member (OR: 4.22; 95\% CI: 3.47-5.13) facilities. Public facilities, youth organizations, schools, and YMCAs were significantly more likely to be in higher-SES, low-minority block groups.

There was a significant interaction of proportion of the population with college education and of highminority population on all facilities and instructional facilities. The interactive effect of living in a highereducated- and low-minority-population block group was examined across all facilities, and results are presented for the summary facility measure (Table 3). Individuals living in high-minority and low-educated block groups were half as likely (OR: 0.54; 95\% CI: 0.51-0.58) as those in low-minority, higher-educated block groups to have at least 1 PA facility. It is notable that in block groups with highly educated populations, the relative odds of having a PA facility did not differ across various proportions of minority population. However, among low-educated groups, a greater percent minority population was associated with fewer facilities.

Individual level analyses were run to predict the relative odds of overweight and engaging in healthy levels of MVPA, with increasing numbers of PA facilities per block group (Table 4). Relative odds of overweight declined with increasing number of PA facilities per block group. Having just 1 PA facility per block group was associated with a $5 \%$ decrease in the relative odds of overweight relative to having no such facilities (OR: 0.95; 95\% CI: $0.90-0.99 ; P=.018)$. Similarly, the rel- ative odds of achieving $\geq 5$ bouts of MVPA per week increased with each additional PA facility per block group. Having just 1 PA facility was associated with an increased relative odds of engaging in $\geq 5$ bouts of MVPA per week by $3 \%$ relative to having no such facilities (OR: 1.03; 95\% CI: 1.01-1.06; $P=.009)$. Individuals who lived in census-block groups with 7 PA facilities were $32 \%$ less likely to be overweight and $26 \%$ more likely to be highly active than those who lived in block groups with no PA facilities.

\section{DISCUSSION}

This nationally representative study of $>20000$ adolescents and $19 \%$ of all US census-block groups provides the first empirical evidence to suggest that all major categories of PA-related resources are distributed inequitably, with high-minority, low-educated neighborhoods at a strong disadvantage. In addition, this inequitable distribution is significantly associated with subsequent disparities in health-related behaviors and obesity measured at the individual level. Presence of a PA facility in a block group is associated with an increased likelihood of engaging in $\geq 5$ bouts of MVPA per week and a decreased relative odds of overweight. In addition, there is a significant beneficial effect linked with each additional PA facility.

Of particular relevance is the fact that, in addition to all facilities showing inequitable distribution by sociodemographic characteristics, categories of facilities that were expected to be distributed equitably (eg, public facilities, youth organizations, parks, YMCAs, and schools) were actually distributed inequitably. Ethnic minorities and those of lower education are at the highest risk for lack of PA and recreational facilities. These findings, coupled with the association between the availability of these resources at the block-group level and the increased likelihood of engaging in PA and the decreased relative odds of overweight status, suggest that inequality in the built environment might underlie important ethnic and sociodemographic health disparities.

Three recent review articles conclude that environmental factors, measured either objectively or perceptively, are consistently related to PA. ${ }^{29-31}$ Objective and perceived access to facilities and opportunities to exercise are consistent predictors of PA in smaller regional studies. ${ }^{11,32-34}$ One study in a small mid-Western US city shows some association between distribution of facilities and sociodemographic factors. ${ }^{35} \mathrm{~A}$ larger study in Atlanta, GA, ${ }^{7}$ and another using national data at the county and metropolitan level ${ }^{7}$ show an association between the built environment and BMI and PA. Future work needs to determine which specific types of environmental changes are likely to impact PA and obesity, which at present is unknown. ${ }^{30}$

The association between SES and PA, independent of race/ethnicity, has been shown in a variety of popula- 
FIGURE 2

Relative odds of having at least 1 PA facility for every $100 \%$ increase in proportion of population with college or greater education ( $N=42187$; adjusted by population density and proportion minority)

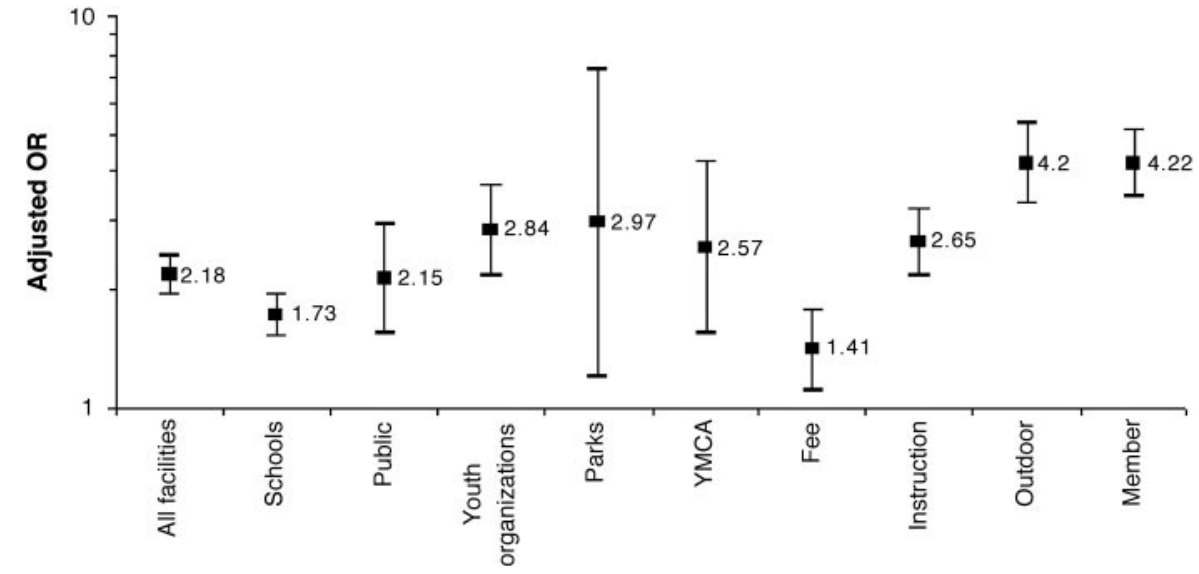

TABLE 3 Relative Odds of Having at Least 1 PA Facility per CensusBlock Group at Various Levels of Minority and Education, Compared to Block Groups With 55\% of Population With College Education or Greater and 5\% Minority Population, Controlling for Population Density

\begin{tabular}{lccc}
\hline & $\begin{array}{c}55 \% \text { College } \\
\text { Educated }\end{array}$ & $\begin{array}{c}25 \% \text { College } \\
\text { Educated }\end{array}$ & $\begin{array}{c}5 \% \text { College } \\
\text { Educated }\end{array}$ \\
\hline $5 \%$ minority & 1.00 & $0.81(0.78-0.84)$ & $0.70(0.66-0.75)$ \\
$25 \%$ minority & $0.98(0.95-1.02)$ & $0.78(0.75-0.81)$ & $0.66(0.63-0.71)$ \\
$95 \%$ minority & $0.93(0.80-1.07)$ & $0.67(0.63-0.72)$ & $0.54(0.51-0.58)$ \\
\hline
\end{tabular}

The values shown are OR $(95 \% \mathrm{Cl}) ; N=42187$.

tions. ${ }^{11,36}$ Although some have suggested that lower-SES communities are located in denser commercial space and therefore have access to more facilities, ${ }^{11,37}$ our research at the national level suggests that this access to commercial space may not translate into access to a variety of recreational facilities across diverse settings. The vast geographic coverage of these national data provide a rare opportunity to examine these relationships at a national level that had not yet been examined.

This cross-sectional ecological study shows crude associations between census-block-level sociodemographics and availability of PA and recreational facilities and advance the association between these facilities and individual-level behaviors. These findings have important policy and intervention implications and emphasize the connection between the built environment and health outcomes.

Although this study investigates the availability of PA and recreational facilities across census-block groups, availability is just one dimension that should be addressed. Affordability, quality, and accessibility, as well as availability, are important. Nonetheless, this study shows that availability alone is associated with a significant increase in bouts of PA and decreased overweight. This is a cross-sectional study, and as such it is impossible to demonstrate that recreational facilities have been distributed inequitably over time. Other factors in the built environment might equally impact obesity and
TABLE 4 Relative Odds of Overweight and MVPA With Increasing Numbers of Facilities per Block Group, Controlling for Population Densitya

\begin{tabular}{ccc}
\hline $\begin{array}{c}\text { No. of } \\
\begin{array}{c}\text { Recreational } \\
\text { Facilities }\end{array}\end{array}$ & $\begin{array}{c}\text { Overweight } \\
\text { Adjusted OR } \\
(95 \% \mathrm{Cl})\end{array}$ & $\begin{array}{c}\geq 5 \text { Bouts } \\
\text { MVPA } \\
\text { Adjusted OR } \\
(95 \% \mathrm{Cl})\end{array}$ \\
\hline 1 & $0.95(0.90-0.99)$ & $1.03(1.01-1.06)$ \\
2 & $0.90(0.82-0.98)$ & $1.07(1.02-1.21)$ \\
3 & $0.85(0.74-0.97)$ & $1.10(1.03-1.19)$ \\
4 & $0.80(0.67-0.96)$ & $1.14(1.03-1.26)$ \\
5 & $0.76(0.60-0.95)$ & $1.18(1.04-1.33)$ \\
6 & $0.72(0.55-0.95)$ & $1.22(1.05-1.41)$ \\
7 & $0.68(0.49-0.94)$ & $1.26(1.06-1.50)$ \\
\hline
\end{tabular}

Overweight $(N=17950)$ was defined as a BMI $\geq 95$ th percentile of the CDC/NCHS 2000 growth curves, and nonoverweight was defined as a BMl $<95$ th percentile; high MVPA ( $N=$ 18413) was defined as $\geq 5$ bouts of MVPA per week, and low MVPA was defined as $<5$ bouts of MVPA per week. SEs were corrected for the complex survey design.

a Referent group $=0$ facilities in block group.

obesity-related behaviors. Some work suggests a similar relationship between inequitable distribution of grocery stores by SES and race/ethnicity, ${ }^{38,39}$ and these factors are not considered in the present study. Our future work will delve deeper into measures of the built environment that were not captured in this study (eg, neighborhood walkability, land use, community design) at the individual, as opposed to the ecological, level.

These findings suggest that a wide range of US PA and recreational facilities may be distributed inequitably by ethnicity and SES, with additional association with individual-level behaviors. It is imperative that intervention efforts address the disparities in access to facilities and the relationship between the built environment and obesity and PA. Increasing the availability of PA and recreational facilities in underserved communities may be a profitable strategy for increasing PA and decreasing overweight at a population level.

\section{ACKNOWLEDGMENTS}

Funding for this study and for development of the preliminary spatial data comes from the National Institutes 
of Health (National Institute of Child Health and Human Development grants R01 HD39183-01, R01 HD04137501, and K01 HD044263-01; National Institute of Diabetes and Digestive and Kidney Diseases grant DK56350; and National Institute on Environmental Health Sciences grant P30ES10126) and a cooperative agreement with the Centers for Disease Control and Prevention (CDC SIP No. 5-00). None of the organizations funding the investigators had any role in the design and conduct of the study; collection, management, analysis, and interpretation of the data; or preparation, review, or approval of the manuscript.

We thank Ms Frances Dancy for helpful administrative assistance. This research uses data from Add Health, a program project designed by J. Richard Udry, Peter S. Bearman, and Kathleen Mullan Harris, from the National Institute of Child Health and Human Development, with cooperative funding from 17 other agencies. Special acknowledgment is due to Ronald R. Rindfuss and Barbara Entwisle for assistance in the original design.

\section{REFERENCES}

1. Gordon-Larsen P, Adair L, Popkin BM. The relationship between ethnicity, socioeconomic factors, and overweight: the National Longitudinal Study of Adolescent Health. Obes Res. 2003;11:121-129

2. Mokdad AH, Ford ES, Bowman BA, et al. Prevalence of obesity, diabetes, and obesity-related health risk factors, 2001. JAMA. 2003;289:76-79

3. Yen IH, Kaplan GA. Poverty area residence and changes in physical activity level: evidence from the Alameda County Study. Am J Public Health. 1998;88:1709-1712

4. Diez Roux AV, Merkin SS, Arnett D, et al. Neighborhood of residence and incidence of coronary heart disease. $N$ Engl J Med. 2001;345:99-106

5. Ewing R, Schmid T, Killingsworth R, Zlot A, Raudenbush S. Relationship between urban sprawl and physical activity, obesity, and morbidity. Am J Health Promot. 2003;18:47-57

6. Huston SL, Evenson KR, Bors P, Gizlice Z. Neighborhood environment, access to places for activity, and leisure-time physical activity in a diverse North Carolina population. Am J Health Promot. 2003;18:58-69

7. Frank LD, Andresen MA, Schmid TL. Obesity relationships with community design, physical activity, and time spent in cars. Am J Prev Med. 2004;27:87-96

8. Gordon-Larsen P, McMurray RG, Popkin BM. Determinants of adolescent physical activity and inactivity patterns. Pediatrics. 2000;105(6). Available at: www.pediatrics.org/cgi/content/ full/105/6/e83

9. Brownson RC, Baker EA, Houseman RA, Brennan LK, Bacak SJ. Environmental and policy determinants of physical activity in the United States. Am J Public Health. 2001;91:1995-2003

10. Booth ML, Owen N, Bauman A, Clavisi O, Leslie E. Socialcognitive and perceived environmental influences associated with physical activity in older Australians. Prev Med. 2001;31: $15-22$

11. Giles-Corti B, Donovan RJ. The relative influence of individual, social and physical environment determinants of physical activity. Soc Sci Med. 2002;54:1793-1812

12. US Department of Health and Human Services. The Surgeon General's Call to Action to Prevent and Decrease Overweight and
Obesity. Washington, DC: US Government Printing Office; 2001. Available at: www.surgeongeneral.gov/topics/obesity/ calltoaction/CalltoAction.pdf. Accessed November 17, 2005

13. Robert Wood Johnson Foundation. Active living research: research overview. Available at: www.activelivingresearch.org/ index.php/Research_Overview/171. Accessed October 11, 2004

14. Marmot M. Inequalities in health. $N$ Engl J Med. 2001;345: $134-136$

15. Longley PA, Goodchild MF, Maguire DJ, Rhind DW. Geographic Information Systems and Science. New York, NY: Wiley; 2001

16. Antonakos CL. Nonmotor travel in the 1990 National Personal Transportation Survey. Transportation Res Rec. 1995;1502: 75-82

17. Sallis JF, Hovell MF, Hofstetter CR, et al. Distance between homes and exercise facilities related to frequency of exercise among San Diego residents. Public Health Rep. 1990;105:179-185

18. Popkin BM, Zizza C, Siega-Riz AM. Who is leading the change? United States dietary trends 1965-96. Am J Prev Med. 2003;25:1-8

19. Winkleby MA, Jatulis DE, Frank E, Fortmann SP. Socioeconomic status and health: how education, income, and occupation contribute to risk factors for cardiovascular disease. Am J Public Health. 1992;82:816-820

20. Pratt M, Macera CA, Blanton C. Levels of physical activity and inactivity in children and adults in the United States: current evidence and research issues. Med Sci Sports Exerc. 1999;31(11 suppl):S526-S533

21. Gordon-Larsen P, Nelson MC, Popkin BM. Longitudinal physical activity and sedentary behavior trends: adolescence to adulthood. Am J Prev Med. 2004;27:277-283

22. Andersen RE, Crespo CH, Bartlett SJ, Cheskin LJ, Pratt M. Relationship of physical activity and television watching with body weight and level of fatness among children: results from the Third National Health and Nutrition Examination Survey. JAMA. 1998;279:938-942

23. Baranowski T. Validity and reliability of self-report measures of physical activity: an information processing perspective. Res $Q$ Exerc Sport 1988;59:314-327

24. Pate RR, Heath GW, Dowda M, Trost SG. Associations between physical activity and other health behaviors in a representative sample of US adolescents. Am J Public Health. 1996;86: 1577-1581

25. Sallis JF, Buono MJ, Roby JJ, Micale FG, Nelson JA. Seven-day recall and other physical activity self-reports in children and adolescents. Med Sci Sports Exerc. 1993;25:99-108

26. Centers for Disease Control and Prevention, National Center for Health Statistics. CDC growth charts: United States. Available at: www.cdc.gov/nchs/about/major/nhanes/growthcharts/ charts.htm. Accessed May 30, 2000

27. Goodman E, Strauss RS. Self-reported height and weight and the definition of obesity in epidemiologic studies. J Adolesc Health. 2003;33:140-141

28. Stata [computer program]. Version 8.2. College Station, TX; Stata Corp: 2003

29. Saelens BE, Sallis JF, Frank LD. Environmental correlates of walking and cycling: findings from the transportation, urban design, and planning literatures. Ann Behav Med. 2003;25: $80-91$

30. Humpel N, Owen N, Leslie E. Environmental factors associated with adults' participation in physical activity: a review. Am J Prev Med. 2002;22:188-199

31. Sallis JF, Prochaska JJ, Taylor WC. A review of correlates of physical activity of children and adolescents. Med Sci Sports Exerc. 2000;32:963-973

32. Evenson KR, Sarmiento OL, Tawney KW, Macon ML. Personal, social, and environmental correlates of physical activity in North Carolina Latina immigrants. Am J Prev Med. 2003;25(3 suppl 1):77-85 
33. Ainsworth BE, Wilcox S, Thompson WW, Richter DL, Henderson KA. Personal, social, and physical environmental correlates of physical activity in African-American women in South Carolina. Am J Prev Med. 2003;25(3 suppl 1):23-29

34. Humpel N, Owen N, Leslie E, Marshall A, Bauman A, Sallis JF. Associations of location and perceived environmental attributes with walking in neighborhoods. Am J Health Promot. 2004; 18:239-242

35. Estabrooks PA, Lee RE, Gyurcsik NC. Resources for physical activity participation: does availability and accessibility differ by neighborhood socioeconomic status? Ann Behav Med. 2003; 25:100-104

36. Parks SE, Houseman RA, Brownson RC. Differential correlates of physical activity in urban and rural adults of various socioeconomic backgrounds in the United States. J Epidemiol Community Health. 2003;57:29-35

37. Wilson DK, Kirtland KA, Ainsworth BE, Addy CL. Socioeconomic status and perceptions of access and safety for physical activity. Ann Behav Med. 2004;28:20-28

38. Morland K, Wing S, Diez-Roux A, Poole C. Neighborhood characteristics associated with the location of food stores and food service places. Am J Prev Med. 2002;22:23-29

39. Morland K, Wing S, Roux A. The contextual effect of the local food environment on residents' diets: the Atherosclerosis Risk in Communities study. Am J Public Health. 2002; 92:1761-1768 


\title{
Inequality in the Built Environment Underlies Key Health Disparities in Physical
} Activity and Obesity

Penny Gordon-Larsen, Melissa C. Nelson, Phil Page and Barry M. Popkin

Pediatrics 2006;117;417

DOI: $10.1542 /$ peds.2005-0058

\author{
Updated Information \& \\ Services \\ References \\ including high resolution figures, can be found at: \\ http://pediatrics.aappublications.org/content/117/2/417 \\ This article cites 33 articles, 1 of which you can access for free at: \\ http://pediatrics.aappublications.org/content/117/2/417.full\#ref-list-1 \\ Subspecialty Collections \\ This article, along with others on similar topics, appears in the \\ following collection(s): \\ Endocrinology \\ http://classic.pediatrics.aappublications.org/cgi/collection/endocrinol \\ ogy_sub \\ Environmental Health \\ http://classic.pediatrics.aappublications.org/cgi/collection/environme \\ ntal_health_sub \\ Adolescent Health/Medicine \\ http://classic.pediatrics.aappublications.org/cgi/collection/adolescent \\ health:medicine_sub \\ Obesity \\ http://classic.pediatrics.aappublications.org/cgi/collection/obesity_ne \\ w_sub \\ Permissions \& Licensing \\ Information about reproducing this article in parts (figures, tables) or \\ in its entirety can be found online at: \\ https://shop.aap.org/licensing-permissions/ \\ Reprints \\ Information about ordering reprints can be found online: \\ http://classic.pediatrics.aappublications.org/content/reprints
}

Pediatrics is the official journal of the American Academy of Pediatrics. A monthly publication, it has been published continuously since. Pediatrics is owned, published, and trademarked by the American Academy of Pediatrics, 141 Northwest Point Boulevard, Elk Grove Village, Illinois, 60007. Copyright @ 2006 by the American Academy of Pediatrics. All rights reserved. Print ISSN: 


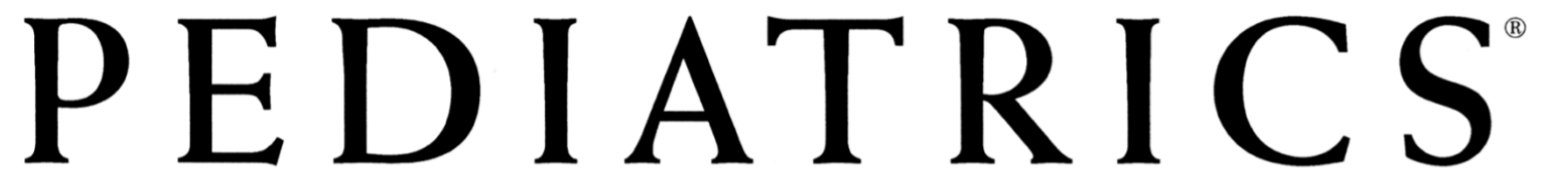

OFFICIAL JOURNAL OF THE AMERICAN ACADEMY OF PEDIATRICS

\section{Inequality in the Built Environment Underlies Key Health Disparities in Physical} Activity and Obesity

Penny Gordon-Larsen, Melissa C. Nelson, Phil Page and Barry M. Popkin

Pediatrics 2006; $117 ; 417$

DOI: $10.1542 /$ peds.2005-0058

The online version of this article, along with updated information and services, is located on the World Wide Web at:

http://pediatrics.aappublications.org/content/117/2/417

Pediatrics is the official journal of the American Academy of Pediatrics. A monthly publication, it has been published continuously since. Pediatrics is owned, published, and trademarked by the American Academy of Pediatrics, 141 Northwest Point Boulevard, Elk Grove Village, Illinois, 60007. Copyright (C 2006 by the American Academy of Pediatrics. All rights reserved. Print ISSN: 